\title{
Oblique effect in visual mismatch negativity
}

\author{
Endre Takács ${ }^{1,2 *}$, István Sulykos ${ }^{1,2}$, István Czigler ${ }^{1,2}$, Irén Barkaszi ${ }^{1,3}$ and László Balázs ${ }^{1}$ \\ ${ }^{1}$ Research Centre for Natural Sciences, Institute of Cognitive Neuroscience and Psychology, Hungarian Academy of Sciences, Budapest, Hungary \\ 2 Faculty of Education and Psychology, Eötvös Loránd University, Budapest, Hungary \\ ${ }^{3}$ Department of Cognitive Psychology, Institute of Psychology, Eötvös Loránd University, Budapest, Hungary
}

\section{Edited by:}

Piia Astikainen, University of Jyväskylä, Finland

\section{Reviewed by:}

Helen Clery, Institut National de la

Santé et de la Recherche Médicale,

France

Dagmar Müller, University of

Leipzig, Germany

*Correspondence:

Endre Takács, Research Centre for

Natural Sciences, Institute of

Cognitive Neuroscience and

Psychology, Hungarian Academy of

Sciences, Pusztaszeri Str., 59-67,

1394 Budapest, P.O. Box 398,

Hungary

e-mail: takacs.endre@ttk.mta.hu
We investigated whether visual orientation anisotropies (known as oblique effect) exist in non-attended visual changes using event-related potentials (ERP). We recorded visual mismatch negativity (VMMN) which signals violation of sequential regularities. In the visual periphery unattended, task-irrelevant Gábor patches were displayed in an oddball sequence while subjects performed a tracking task in the central field. A moderate change $\left(50^{\circ}\right)$ in the orientation of stimuli revealed no consistent change-related components. However, we found orientation-related differences around $170 \mathrm{~ms}$ in occipito-temporal areas in the amplitude of the ERPs evoked by standard stimuli. In a supplementary experiment we determined the amount of orientation difference that is needed for change detection in an active, attended paradigm. Results exhibited the classical oblique effect; subjects detected $10^{\circ}$ deviations from cardinal directions, while threshold from oblique directions was $17^{\circ}$. These results provide evidence that perception of change could be accomplished at significantly smaller thresholds, than what elicits vMMN. In Experiment 2 we increased the orientation change to $90^{\circ}$. Deviant-minus-standard difference was negative in occipito-parietal areas, between 120 and 200 ms after stimulus onset. VMMNs to changes from cardinal angles were larger and more sustained than vMMNs evoked by changes from oblique angles. Changes from cardinal orientations represent a more detectable signal for the automatic change detection system than changes from oblique angles, thus increased vMMN to these "larger" deviances might be considered a variant of the magnitude of deviance effect rarely observed in vMMN studies.

Keywords: visual mismatch negativity (vMMN), event-related potential (ERP), unconscious processing, attention, oblique effect, oddball paradigm

\section{INTRODUCTION}

Oblique effect, a well-known phenomenon in visual orientation research, denotes that the nervous system is more sensitive to stimuli of cardinal (vertical and horizontal) than oblique orientations. Various experimental methods demonstrate this anisotropy, e.g., contrast sensitivity for gratings (Campbell et al., 1966; Caelli et al., 1983), visual acuity (Berkley et al., 1975), vernier acuity (Corwin et al., 1977), setting stimuli parallel (Andrews, 1967) and reproduction of stimulus orientation (Gentaz et al., 2001).

The oblique effect most likely originates from the visual cortex (Li et al., 2003, but see Vidyasagar and Urbas, 1982). In a wide range of mammal species more cells respond preferably to cardinal than to oblique stimuli in the visual cortex (Mansfield, 1974; Levitt et al., 1994; Coppola et al., 1998; Li et al., 2003; Xu et al., 2006). The fact that oblique effect emerges if light is projected straight to retina indicates that not the optics of the eyeball or pupil is responsible for the effect (Campbell et al., 1966; Mitchell et al., 1967).

In humans, larger fMRI response was registered to cardinal than to oblique stimuli in V1 (Furmanski and Engel, 2000). Using event-related potentials (ERP) unequal responses have been obtained to cardinal and oblique orientations in steady state potentials (Maffei and Campbell, 1970; May et al., 1979;
Skrandies, 1984; Moskowitz and Sokol, 1985); transient ERPs (Yoshida et al., 1975; Arakawa et al., 2000; Proverbio et al., 2002), and MEG (Koelewijn et al., 2011).

Orientation anisotropies were also demonstrated in visual search. In these experiments an oblique stimulus pops out more easily among vertical stimuli, than a vertical stimulus among oblique stimuli (Treisman and Gormican, 1988; Cavanagh et al., 1990). According to the interpretation by Treisman and Gormican, 1988, the visual system treats vertical lines as default, primary value, while oblique lines carry an additional feature (vertical plus a deviancy from vertical). These features are perceived preattentively, without the need of individual examination of every element in the display. On the contrary, the lack of features could only be detected with serial inspection of every stimuli, so increasing the number of distractor elements monotonically increases the reaction time. These results imply that there are essential differences between oblique and vertical orientations. It is important to note that the direction of the asymmetry switches if an aperture is placed over the display having the same orientation as the oblique stimuli, i.e., in this case the vertical stimulus pops-out. However, installing a rounded aperture which is neutral in orientation, oblique stimulus pops-out again, demonstrating that the basis of the phenomenon is the oblique effect, but environmental clues have also important roles. Others 
have pointed out the influence of vestibular and somatosensory input (Marendaz, 1998; Lipshits and McIntyre, 1999).

In the majority of papers dealing with the oblique effect, stimuli were in the focus of attention, however, the visual search anisotropy indicates that the oblique effect may also be present at the pre-attentive levels. Investigation of the automatic visual change-detection may also underpin that oblique effect is a fundamental phenomenon in visual perception.

Automatic, unconscious deviance-detection is indicated by the auditory (MMN, for review see Näätänen and Winkler, 1999; Näätänen et al., 2007) and visual mismatch negativities (vMMN, for review see Pazo-Alvarez et al., 2003; Czigler, 2007; Kimura et al., 2011). VMMN is usually investigated in the passive oddball paradigm, where standard stimuli are infrequently replaced by deviant stimuli. VMMN might be recorded in various experimental conditions. In one subset of experiments, vMMN-related stimuli are presented in the unattended, task-irrelevant part of the visual field, while subjects are engaged in a task presented in the center of the visual field (e.g., Tales et al., 1999; Czigler et al., 2002). In other type of experiments a single object is presented and certain features, like the shape of a line segment's end, are used for the task while some other features, like the orientation of the line, are used for vMMN elicitation (e.g., Kimura et al., 2010a). VMMN also emerges in conditions when subjects perform a primary auditory task concurrently with unattended visual stimuli (e.g., Astikainen et al., 2004). In most cases vMMN is a negative component within the $120-400 \mathrm{~ms}$ latency range over posterior areas, identified in the deviant minus standard difference wave of ERPs. Auditory and visual MMN is considered to emerge whenever the regularity of the incoming discrete elements is automatically registered, and as a result of comparison processes the violation of the regularity by a new event is detected (Winkler and Czigler, 2012). Upon detecting such mismatch, MMN or vMMN emerges reflecting a prediction error.

At least one portion of both the auditory and visual MMN originates from sensory areas of the brain. Studies aimed to localize vMMN (Yucel et al., 2007; Kimura et al., 2010b; Urakawa et al., 2010; Müller et al., 2012) are in agreement that it has generators in the visual cortex. Deviant-related negative components on occasion found in anterior electrode sites (Czigler et al., 2004; Clery et al., 2012), frontal sources have been demonstrated as well with fMRI (Clery et al., 2013; Cléry et al., 2013) and LORETA (Kimura et al., 2010b). VMMN could be elicited with simple visual deviances, such as motion direction (Pazo-Alvarez et al., 2004), orientation, spatial frequency (Heslenfeld, 2003), color (Czigler et al., 2002), or shape (Maekawa et al., 2005). Studies utilizing orientation change are relatively numerous (Astikainen et al., 2004, 2008; Czigler and Pató, 2009; Flynn et al., 2009; Kimura et al., 2009, 2010a; Czigler and Sulykos, 2010; Sulykos and Czigler, 2011; Sulykos et al., 2013).

In this study we set out to investigate the possibility of orientation anisotropies in vMMN. In a series of experiments we examined whether the system underlying vMMN was more sensitive to orientation deviations from cardinal than from oblique angles. In the first experiment we used a modest change of orientation $\left(50^{\circ}\right)$. While subjects performed a visuomotor tracking task in the center of the visual field, Gábor patches with various orientations were presented in the periphery in an oddball sequence. Infrequent changes in orientation occurred in oblique vs. cardinal as well as in oblique vs. oblique relation. Our main hypothesis was that visual deviance detection is easier if change occurs compared to cardinal than compared to oblique angles, and this will manifest itself in increased vMMN to such changes. This would be in concordance with the findings and theory of Treisman and Gormican (1988). We also expected reduced vMMN to changes from oblique to oblique orientations compared to the other two relations involving cardinal stimuli, as it is suggested by the oblique literature. We also investigated if the oblique effect is manifested in the exogenous ERP components.

We considered the tracking task to be especially appropriate, because this task guarantees continuous and constant attentional demand, while the vMMN-related stimuli are presented as separate, individual objects in a separate part of the visual field. Taking into account the frame effects reported in visual search studies (Treisman and Gormican, 1988), sources of visual orientation were eliminated from the experimental environment by placing a black circular aperture over the computer screen, and by providing no background light in the room.

Following the first electrophysiological experiment we conducted a psychophysical measurement in order to assess the threshold for orientation change detection in an active paradigm with stimuli similar to those used in the passive oddball experiment (i.e., Gábor patches). In addition, the psychophysical measurement allowed us to assess an observation reported earlier, that in contrast to auditory modality where MMN is thought to be elicited by any discriminable difference (Sams et al., 1985; Näätänen et al., 2007), in the visual modality significantly larger differences are necessary to evoke vMMN. For example, in a study by Czigler et al. (2002) pink-black grating changing to red-black grating elicited no vMMN, although in an active paradigm it is easy to detect such color change.

\section{EXPERIMENT 1 \\ METHODS \\ Participants}

Seventeen healthy students volunteered in this experiment (12 females, mean age: 22.5 years, age range: $18-32$ years) either for modest financial compensation or for course credit. All subjects had normal or corrected-to-normal vision and have given written informed consent after the nature of the experiment had been explained to them. The experiment was approved by the Joint Ethical Committee of the Hungarian Psychology Institutes.

\section{Stimuli and procedure}

Task-irrelevant stimuli. Task-irrelevant stimuli were Gábor patches (circular grayscale images of Gaussian-windowed sinusoidal gratings; Gaussian standard deviation: 0.17; phase: $45^{\circ}$; trim-value: 0.25 , spatial frequency: 3 ) in two concentric circles (see Figure 1). A circular aperture (radius: $6.2^{\circ}$ ) was placed over the monitor in order to remove all external orientation clues. The first circle from the center of the screen had 12 patches (diameter: $1.6^{\circ}$ ). The second, outer circle consisted of 16 patches (diameter: $\left.1.9^{\circ}\right)$. Measured from the center of the screen to the center 


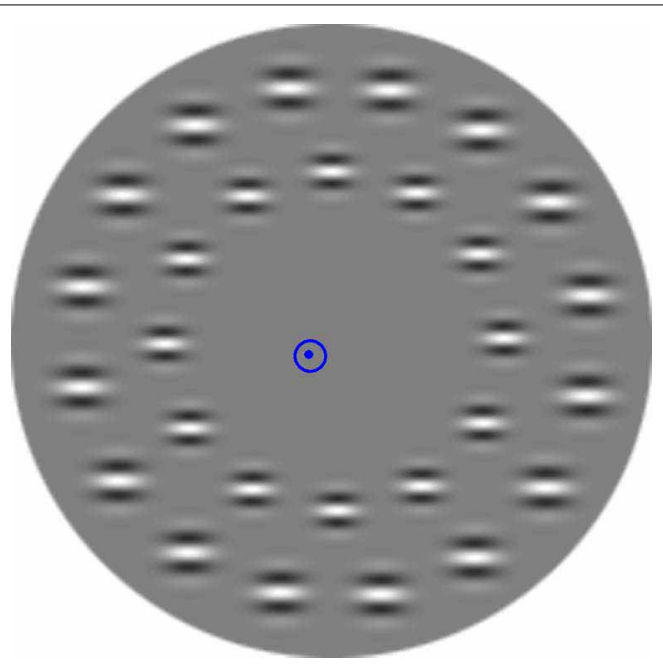

FIGURE 1 | An example of the display.

of the patches, the distance was 3.4 and $5.2^{\circ}$. Care was taken to avoid that the inner and outer circle's patches create radiant lines that could ground for orientation. The background was gray $\left(3.1 \mathrm{~cd} / \mathrm{m}^{2}\right)$. Stimulus display time was $100 \mathrm{~ms}$, inter-stimulus time was $450 \pm 50 \mathrm{~ms}$ random jitter to avoid evoking steady state potentials. ERPs were recorded to these task-irrelevant stimuli.

Task-relevant stimuli. Subjects performed a tracking task in the center in a circular task field $\left(1.3^{\circ}\right)$. They were asked to keep an ever-moving dot inside a small circle by tracking down its moves using a trackball (Kensington, Orbit optical trackball). When the dot was inside the circle, the circle was blue $\left(0.9 \mathrm{~cd} / \mathrm{m}^{2}\right)$, but in case of getting out, the circle switched to red $\left(6.6 \mathrm{~cd} / \mathrm{m}^{2}\right)$.

Subjects were seated in a reclining chair in a sound-attenuated room, $1.2 \mathrm{~m}$ from an $17^{\prime} \mathrm{LCD}$ monitor (refresh rate: $60 \mathrm{~Hz}$ ). No background light was provided in the room.

Task-irrelevant Gábor patches were placed in a pseudorandom oddball sequence, where standards had $83.1 \%$ probability. Deviant stimuli were preceded by 3-7 standard stimuli. In one block there were 374 standard and 76 deviant stimuli. Every block was presented twice. As Table 1 illustrates, eight types of standard-deviant pairs were tested: 0 vs. $50^{\circ}$ (left from horizontal) (and vice versa), 22.5 vs. $72.5^{\circ}$ (and vice versa), 90 vs. $140^{\circ}$ (and vice versa) and 112.5 vs. $162.5^{\circ}$ (and vice versa). In total 20 blocks were presented, each were approximately 4 min duration. The order of blocks was counterbalanced across participants.

ERP recording. EEG was recorded with NeuroScan system, DC- $100 \mathrm{~Hz}$, sampling rate $500 \mathrm{~Hz}$, with $\mathrm{Ag} / \mathrm{AgCl}$ electrodes in an elastic electrode cap (EasyCap) on 61 channels from standard locations of extended 10-20 system. Ground electrode was attached to lower forehead, reference electrode was placed on the nose-tip. Reference was offline recalculated to channel average. Horizontal and vertical EOG was recorded with a bipolar montage below and lateral to the eyes. EEG was filtered offline using a bandpass filter of 0.1 and $30 \mathrm{~Hz}$ (24 dB/octave slope).
Table 1 | Stimuli in the oddball and "standards only" sequences in Experiment 1.

\begin{tabular}{|c|c|c|c|c|}
\hline \multirow[b]{2}{*}{ Oddball1 } & \multicolumn{2}{|c|}{ Standard } & \multicolumn{2}{|c|}{ Deviant } \\
\hline & $0^{\circ}$ & - & $50^{\circ}$ & I \\
\hline Oddball2 & $50^{\circ}$ & 1 & $0^{\circ}$ & 一 \\
\hline Oddball3 & $22.5^{\circ}$ & 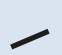 & $72.5^{\circ}$ & I \\
\hline Oddball4 & $72.5^{\circ}$ & I & $22.5^{\circ}$ & r \\
\hline Oddball5 & $90^{\circ}$ & I & $140^{\circ}$ & $\searrow$ \\
\hline Oddball6 & $140^{\circ}$ & 1 & $90^{\circ}$ & 1 \\
\hline Oddball7 & $112.5^{\circ}$ & 1 & $162.5^{\circ}$ & - \\
\hline Oddball8 & $162.5^{\circ}$ & - & $112.5^{\circ}$ & 1 \\
\hline $\begin{array}{l}\text { Standards } \\
\text { only1 }\end{array}$ & $45^{\circ}$ & 1 & & \\
\hline $\begin{array}{l}\text { Standards } \\
\text { only2 }\end{array}$ & $67.5^{\circ}$ & / & & \\
\hline $\begin{array}{l}\text { Standards } \\
\text { only3 }\end{array}$ & $135^{\circ}$ & 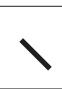 & & \\
\hline $\begin{array}{l}\text { Standards } \\
\text { only4 }\end{array}$ & $167.5^{\circ}$ & - & & \\
\hline
\end{tabular}

Line segments solely illustrate the orientation of Gábor patches. The standarddeviant pairs highlighted by the same color were used to calculate difference waves.

EEG and EOG activities were averaged for epochs beginning $100 \mathrm{~ms}$ before and extending until $400 \mathrm{~ms}$ after stimulus onset. The mean voltage of the first $100 \mathrm{~ms}$ served as baseline interval. Epochs containing amplitude changes exceeding $50 \mu \mathrm{V}$ at any channel were rejected from analysis. Standards preceded by at least three other standards were averaged. ERPs recorded in "standards only" sequences were all averaged, regardless their positions. After artifact rejection for deviants in average 126.5 epochs $(S D=20.0$; range: $64-148)$, for standards 226.7 epochs $(S D=$ 36.9; range: 112-267) and for the "standards only" 153.6 epochs $(S D=26.8$; range: $46-178)$ were included in the mean for one subject.

Analysis. To analyze change-related activities, we calculated difference waves by subtracting ERPs elicited by the very same stimulus as a deviant and a standard (Kujala et al., 2007). Table 1 depicts how the difference waves were calculated. Pairs of standard and deviant stimuli are highlighted in different colors which were used to calculate the difference waves that formed the basis of further analyses. For instance, difference wave for horizontal stimuli $\left(0^{\circ}\right)$ was calculated by subtracting Oddball1 sequence standard ERPs from Oddball2 sequence deviant ERPs. Though, these ERPs were recorded in separate blocks, this way physically 
same stimuli were subtracted from each other, the only difference between them was their roles of being a standard or a deviant.

In two conditions stimuli changed from oblique to cardinal $^{1}$ ( 0 and $90^{\circ}$ ), in other two conditions from cardinal to oblique (50 and $140^{\circ}$ ), and in four conditions from oblique to oblique $\left(22.5,72.5,112.5\right.$, and $\left.162.5^{\circ}\right)$. Additional four orientations (45, $67.5,135$, and $167.5^{\circ 2}$ ) were presented in separate blocks without deviants ("standards only" conditions).

Negative going difference-waves were considered to be valid vMMN responses if point-by-point $t$-test (see, e.g., Guthrie and Buchwald, 1991) were significant at 0.05 level at least at two adjacent parieto-occipital channels in five consecutive time points (10 ms) between 100 and $250 \mathrm{~ms}$ after stimulus onset.

For orientation-related amplitude differences we compared the mean amplitude of standard stimuli in $40 \mathrm{~ms}$ wide time windows centered around the latency of $\mathrm{N} 1 \mathrm{~b}$ subcomponent on six parieto-occipital channels (PO7, POz, PO8, and $\mathrm{O} 1, \mathrm{Oz}$, $\mathrm{O} 2$ ), where this component was most evident by visual inspection. For linear regression models we report $R^{2}$ coefficient of determination, $F$ - and $p$-values.

Tracking task performance was assessed by calculating tracking efficiency, the percent of time when the dot was located inside the circle. Repeated measures ANOVA were performed to compare tracking efficiency in conditions where stimuli changed from cardinal to oblique $\left(50,140^{\circ}\right)$, from oblique to cardinal $\left(0,90^{\circ}\right)$ and from oblique to oblique orientations $(22.5,72.5,112.5$, and $\left.162.5^{\circ}\right)$.

\footnotetext{
${ }^{1}$ Although for the $0^{\circ}$ vMMN the standards come from a block where stimuli changed from 0 to $50^{\circ}$ (i.e., from cardinal to oblique), according to the widely accepted view in change detection studies, it is the deviancy that determines the condition, which in this case is the rare appearance of the $0^{\circ}$ deviants in successions of $50^{\circ}$ standards (i.e., a change from oblique to cardinal). This reasoning applies to every condition $\left(50^{\circ}\right.$ condition, $90^{\circ}$ condition, etc.)

${ }^{2}$ Accidentally we recorded ERPs to $167.5^{\circ}$ instead of $157.5^{\circ}$, which would have been midmost between 135 and $180^{\circ}$.
}

Greenhouse-Geisser correction was applied when appropriate. Significant interactions were further specified by Tukey HSD posthoc test. Partial eta squared $\left(\eta^{2}\right)$ presents effect size estimates.

\section{RESULTS}

\section{Behavioral results}

Repeated measures ANOVA on tracking efficiency with factor conditions revealed significant effects, $F_{(2,34)}=3.4, p<0.05$, $\eta^{2}=0.17$. Tracking efficiency was $81.4 \%(S E=1.73 \%)$ in blocks where stimuli changed from oblique to cardinal, $80.6 \%$ ( $S E=$ $1.80 \%)$ in blocks where stimuli changed from cardinal to oblique, and $81.8 \%(S E=1.69 \%)$ in blocks where stimuli changed from oblique to oblique orientations. Post-hoc comparison showed that the latter two conditions differed significantly from each other.

\section{ERP results}

The response to standard and deviant stimuli displays a positivitynegativity-positivity sequence on $\mathrm{Oz}$ channel (see Figure 3) that could be identified as $\mathrm{P} 1-\mathrm{N} 1 \mathrm{a}-\mathrm{P} 2$ response. These components peak at 94, 112, and $240 \mathrm{~ms}$, respectively. Between N1a and P2 components at lateral, occipito-temporal channels another negative deflection could be observed with a latency of $170 \mathrm{~ms}$ (N1b).

Visual mismatch negativity. Difference waves for eight stimulus orientations $\left(0,50,22.5,72.5,90,140,112.5,162.5^{\circ}\right)$ were calculated. Point-by-point $t$-tests revealed only four conditions out of eight, where vMMN emerged. Figure 2 displays grandaverage waveforms and topographic voltage maps for vMMN in these conditions. As Table 2 shows, in all four conditions there was an early time interval (latencies between 120 and $140 \mathrm{~ms}$ ) for vMMN. In three conditions, vMMN appeared also in a later time interval, with peak latency falling between 198 and $230 \mathrm{~ms}$.

Exogenous differences. We compared ERPs evoked by standard stimuli in the twelve available orientations: $0,22.5,45,50,67.5$,
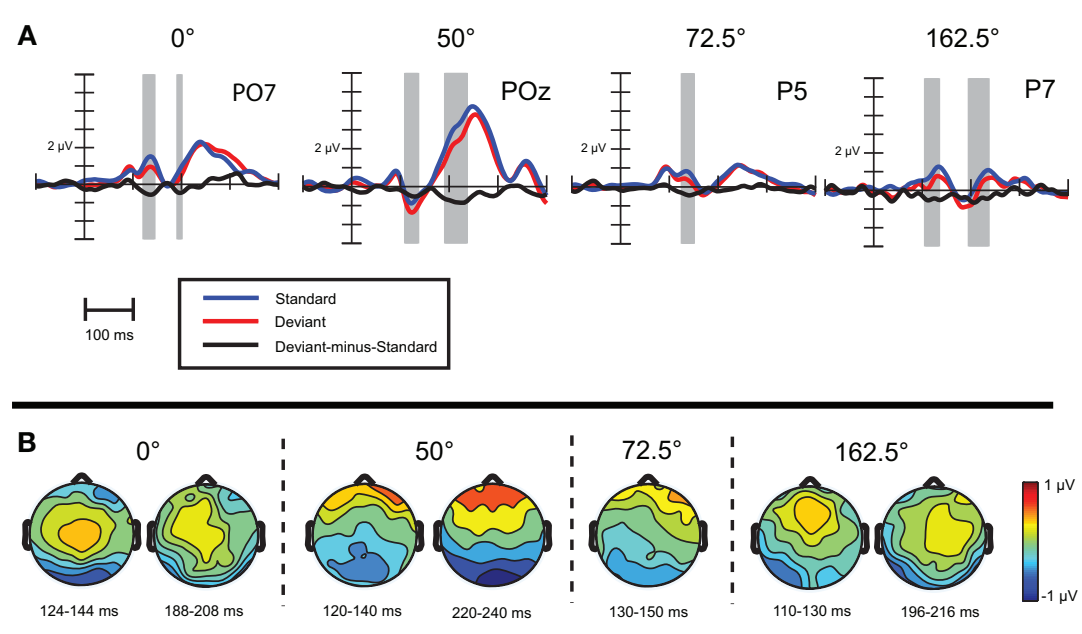

FIGURE 2 | (A) Event-related activity and deviant-minus-standard difference potentials at the location having largest amplitude of the difference potentials in Experiment 1. Intervals marked in gray signaled significant deviant-minus-standard differences by point-by-point $t$-tests. (B) Topographic voltage maps of the deviant-minus-standard difference potentials. 
Table 2 | VMMN in Experiment 1.

\begin{tabular}{|c|c|c|c|c|c|c|}
\hline & \multicolumn{3}{|c|}{ Early time interval } & \multicolumn{3}{|c|}{ Later time interval } \\
\hline $50^{\circ}$ & $\begin{array}{l}\mathrm{P} 1, \mathrm{P} 5, \mathrm{Pz}, \mathrm{P} 2, \mathrm{P} 4 \\
\mathrm{PO} 3, \mathrm{POz}, \mathrm{PO} 4\end{array}$ & 130 & -0.53 & $\begin{array}{l}\text { P5, P3, P2, P4, } \\
\text { P6, P7, PO3, POz, } \\
\text { PO4, P8, PO7, } \\
\text { P08, O1, Oz, O2 }\end{array}$ & 230 & -1.06 \\
\hline $72.5^{\circ}$ & P5, PO3, P3 & 140 & -0.45 & & & \\
\hline $162.5^{\circ}$ & $\mathrm{P} 5, \mathrm{P7}, \mathrm{PO} 3, \mathrm{PO} 7, \mathrm{O} 1$ & 120 & -0.53 & P5, P7, P07, 01 & 206 & -0.55 \\
\hline
\end{tabular}

Channels that exhibited vMMN. Latency and peak amplitude was measured on grand-average waveforms.

$72.5,90,112.5,135,140,162.5$, and $167.5^{\circ}$. To simplify the illustration of the orientation effect, on Figure 3 there are only three orientations, a cardinal $\left(0^{\circ}\right)$ and two oblique angles $\left(22.5,45^{\circ}\right)$.

As Figure 3 illustrates, around $170 \mathrm{~ms}$ (in the time range of the N1b sub-component at occipital channels) there are orientation-related amplitude differences. Although responses were positive in voltage in most cases, N1b subcomponent is a negativity shaped by the adjacent dominant P2 wave. Figure 4 shows mean amplitudes averaged across subjects at PO8 channel, where N1b component reached its maximum. Amplitudes were highly dependent on the orientation of stimuli.

In order to build a linear regression model, we defined a new variable, deviancy from cardinal orientation, which equals to the difference between the given orientation and closest cardinal orientation (e.g., $72.5^{\circ}$ has a $17.5^{\circ}$ deviancy from cardinal orientation, because the closest cardinal orientation is $90^{\circ}$ ). A simple linear regression analysis was conducted at five posterior leads (PO7, O1, Oz, O2, PO8), where we predicted mean amplitudes with the independent variable of deviancy from cardinal orientations. Table 3 displays the results of the regression analyses. The high coefficient of determination $\left(R^{2}\right)$ indicates that the orientation of Gábor patches is a good predictor of the N1b amplitude.

\section{DISCUSSION FOR EXPERIMENT 1}

To conclude, in Experiment 1 vMMNs were evoked sporadically, only in four conditions out of eight. We observed orientation-related amplitude differences in the latency range of occipito-temporal, lateral N1b component, around $170 \mathrm{~ms}$.

Sulykos and Czigler (2011) presented similar Gábor patches in their experiment. Orientation related vMMN was elicited with 130 and $132 \mathrm{~ms}$ peak latency at lower and upper visual field stimulation, respectively. The differences found in the earlier time interval (120-140 ms) in the present study correspond to these latency ranges. However, in the present study we obtained vMMN only in half of the conditions, and there was no oblique-related order in the emergence of deviant-related negativity. Since our hypothesis
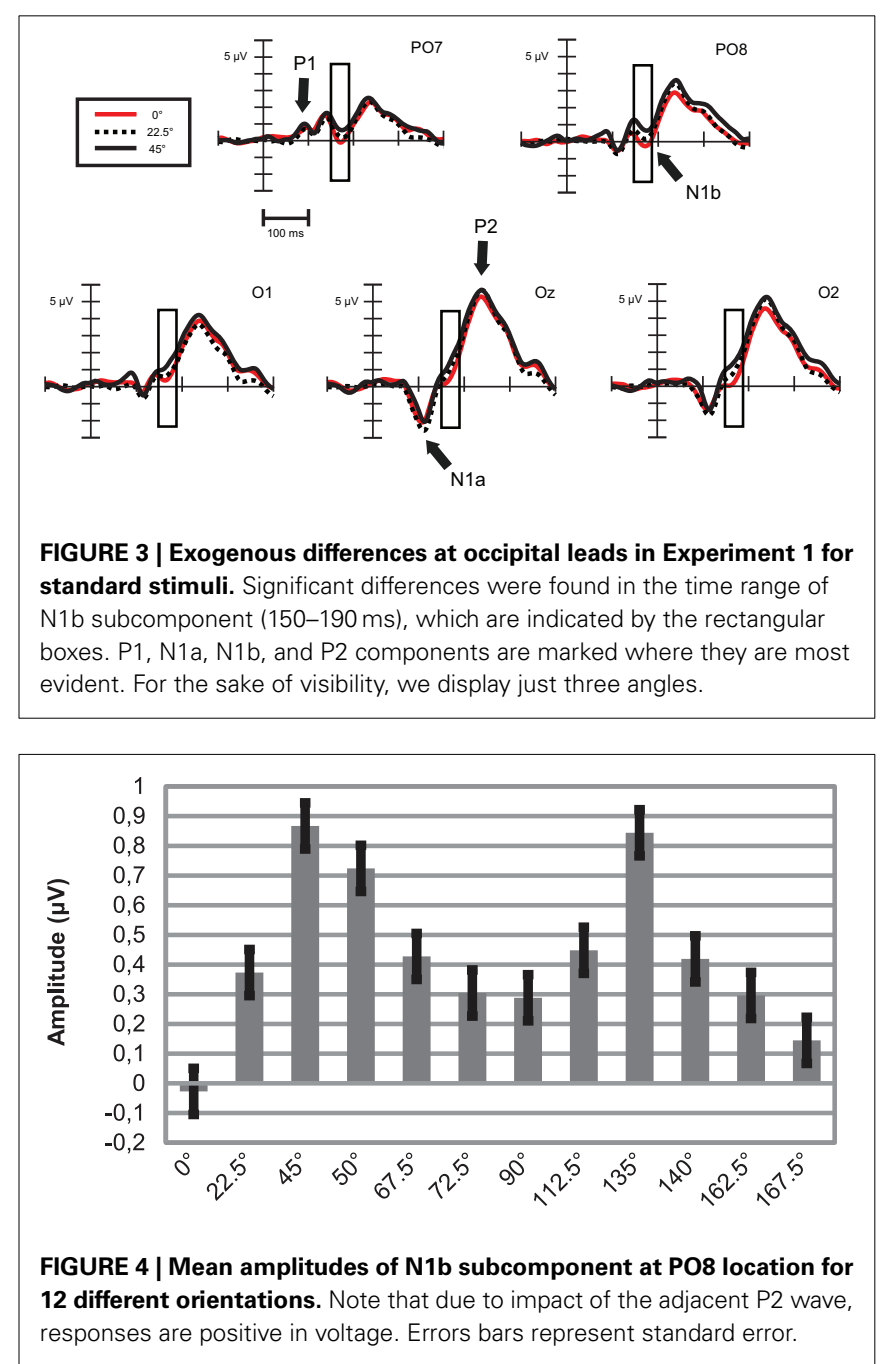

was based on finding valid vMMN responses in all conditions or at least in those involving cardinal stimuli, conclusions pertaining to the existence of oblique effect on vMMN could not be made based on the data of the present experiment. 
Table 3 | Statistics for N1b exogenous differences in Experiment 1.

\begin{tabular}{llll}
\hline & $\boldsymbol{R}^{\mathbf{2}}$ & $\boldsymbol{F}$ & $\boldsymbol{p}$ \\
\hline PO7 & 0.70 & $F_{(1,10)}=23.05$ & $p<0.001$ \\
O1 & 0.61 & $F_{(1,10)}=15.33$ & $p<0.01$ \\
Oz & 0.65 & $F_{(1,10)}=18.64$ & $p<0.01$ \\
O2 & 0.73 & $F_{(1,10)}=26.89$ & $p<0.001$ \\
PO8 & 0.79 & $F_{(1,10)}=38.12$ & $p<0.001$ \\
\hline
\end{tabular}

Linear regression analysis.

Contrary to vMMN, amplitude changes of an exogenous component, the N1b suggest the visual system was able to precisely map the orientation of Gábor patches and ERP methods were suitable for detecting these responses. In the light of these results, the lack of reliable vMMN is even more surprising. It is clear that the processing of orientation did not raise difficulties for the visual system, even if stimuli were in the visual periphery and out of the focus of attention.

The small, but significant difference in tracking efficiency between two conditions (changes from cardinal to oblique vs. changes from oblique to oblique) was an unexpected finding. Czigler and Sulykos (2010) demonstrated subtle interactions between the task-relevant and irrelevant stimuli in a similar experimental setup.

In a supplementary experiment we tried to determine the amount of orientation difference that is needed for change detection in an active, attended paradigm. Subjects were required to detect orientation change of Gábor patches while they were reading aloud numbers in the center appearing simultaneously with the patches. Short (100 ms) and simultaneous display of numbers and Gábor patches prevented subjects from using eye movements to fixate on Gábor patches. In this way subjects detected orientation change through peripheral vision, like in Experiment 1. The tracking task used in Experiment 1 would not have provided the required control over subject's eye movements.

Our goal was to reproduce the classical oblique effect with this type of stimulus array, that is Gábor patches with moderately high spatial frequencies in concentric circles. In addition, we could assess the former observation (Czigler et al., 2002) that vMMN could be registered with significantly larger deviances than what could be detected in an active paradigm.

\section{PSYCHOPHYSICAL MEASUREMENTS METHODS \\ Participants}

Eighteen subjects were recruited in this experiment. Five subjects were excluded due to the high number of false alarms that is more than three false alarms in any of the four blocks. An additional subject was excluded due to very low performance in one block. The final cohort therefore consisted of 12 volunteers ( 7 females, mean age: 21.6 years, age range: $18-30$ years). This sample was partly overlapping with the sample of Experiment 1, eight subjects participated in both experiments.

\section{Stimuli and procedure}

In this experiment the central and peripheral visual field were both task-relevant. The peripheral stimuli were identical to
Experiment 1 stimuli, i.e., Gábor patches in two concentric circles were presented. In the center of the display random numbers from 1 to 9 (color: magenta, $7.8 \mathrm{~cd} / \mathrm{m}^{2}$, size: $0.5^{\circ}$ ) were presented. The background was gray $\left(3.1 \mathrm{~cd} / \mathrm{m}^{2}\right)$. The stimulus duration was $100 \mathrm{~ms}$, inter-stimulus interval was $1500 \mathrm{~ms}$.

The peripheral and central stimuli always appeared simultaneously. The task was to read aloud the numbers while detecting the change in the orientation of the Gábor patches. Participants were instructed to press a button with their dominant hand upon detecting any change in the background. Subjects have been video-monitored in real time by a research assistant to make sure they kept reading aloud the numbers.

Gábor patches were arranged in an oddball sequence. Standards were $0^{\circ}$ (horizontal), 22.5, 90 and $112.5^{\circ}$. Standard probability was $77.8 \%$. At least 2 , at most 5 standards followed a deviant stimulus. Deviant stimuli differed in orientation from standards. Amount of this difference was changing throughout the experiment depending on the subject's response, but deviants were most of the time ${ }^{3}$ oblique orientations. One up, one down staircase sequence was introduced. Until first reversal, step-size was $10^{\circ}$, and then step-size was reduced to $1^{\circ}$. Initial difference was set to $20^{\circ}$ counterclockwise from the standard stimuli. Threshold was calculated as the mean of the last six reversals out of total 11 reversals. Subjects were tested in four blocks for each standard orientation.

The order of blocks was counterbalanced across participants. Prior to this experiment, participants performed Experiment 1, then they had a short break while the EEG-cap was removed and they washed and dried their hair.

\section{RESULTS}

Figure 5 displays mean thresholds. On the mean threshold data of the four conditions we performed a repeated measures ANOVA with factors cardinality (cardinal: $0,90^{\circ}$ vs. oblique $22.5,112.5^{\circ}$ ). A cardinality main effect emerged, $F_{(1,11)}=10.6, p<0.01$, $\eta^{2}=0.49$, reflecting that thresholds were lower when standards were cardinal orientations (threshold: $10.08^{\circ} ; S E=1.99$ ) compared when standards were obliquely oriented (threshold: $16.57^{\circ}$; $S E=2.38)$.

\section{DISCUSSION FOR PSYCHOPHYSICAL MEASUREMENTS}

Thresholds for detecting orientation deviants were 10 and $16.5^{\circ}$ in this experiment. Thresholds were significantly lower when standards were cardinal stimuli (compared when standards were oblique orientations), exhibiting the classical oblique effect. This finding is also in line with the results and theory of Treisman and Gormican (1988).

These thresholds, 10 and $16.5^{\circ}$ are appreciably smaller than the $50^{\circ}$ orientation change that in fact did not elicit reliable vMMN in Experiment 1. These results provide evidence that perception of change in the visual periphery could be accomplished at significantly smaller thresholds, than what elicits vMMN.

\footnotetext{
${ }^{3}$ When e.g., standards were $22.5^{\circ}$ it was possible that deviants had been $90^{\circ}$ for one or more presentations, but as average thresholds $\left(10^{\circ}\right.$ and $\left.16.5^{\circ}\right)$ indicates deviants were fluctuating around $10,39,100$, and $129^{\circ}$ for the $0,22.5,90$, and $112.5^{\circ}$ standard orientations, respectively. Each of these deviants represents oblique orientations.
} 


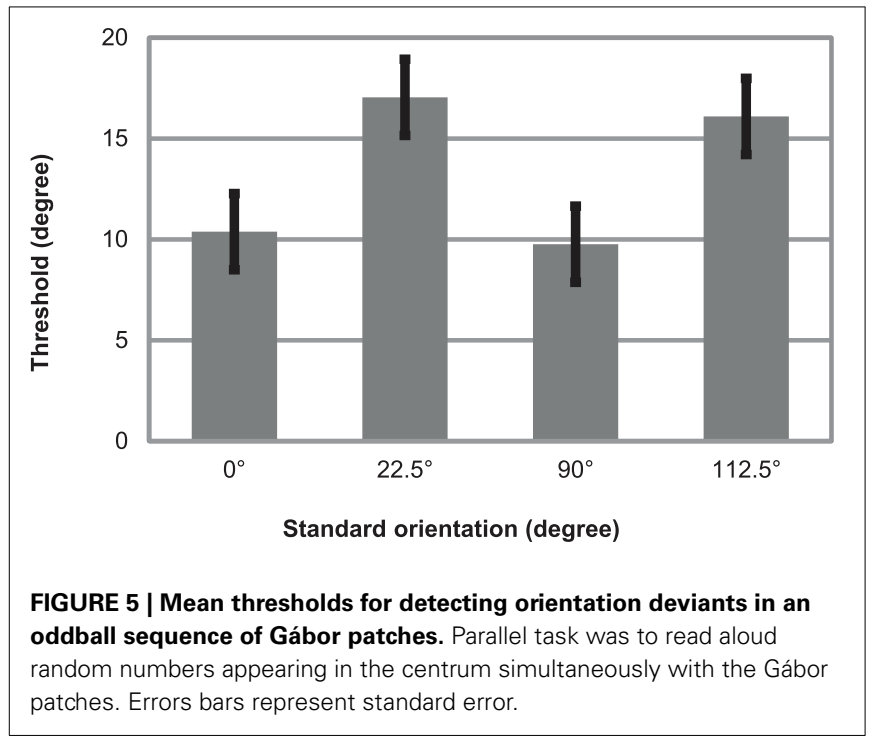

One major difference should be noted between this experiment and the vMMN experiment. Although, in this task central vision was occupied with detecting random numbers, subjects still attended consciously to the Gábor patches. The design of our vMMN experiment is intended to prevent subjects from conscious attention towards stimuli used to elicit ERPs. So these two experiments are really different in a major feature (attentive vs. non-attentive processing), that could account for the markedly different results. However, it is possible that the lack of vMMN is attributable to low signal-to-noise ratio that results from presenting too small orientation change $\left(50^{\circ}\right)$ for reliable vMMN emergence. To test this possibility, and as an attempt to record reliable vMMN, in the next experiment we increased the orientation change to $90^{\circ}$.

\section{EXPERIMENT 2 \\ METHODS \\ Participants}

Nineteen subjects (11 females, mean age: 21.4 years, age range 19-25 years) participated in this experiment. None of them took part in the previous experiments.

\section{Stimuli and procedure}

Task-irrelevant stimuli were similar to stimuli in Experiment 1, with the following exceptions. First, Gábor patches were displayed in three circles ${ }^{4}$, the center of the patches in the first circles were $1.9^{\circ}$ from the center of display and Gábor-patches were $1.3^{\circ}$ in size. The first circle consisted of eight patches. The other two circles and the task-relevant stimuli were identical to Experiment 1 .

As shown in Table 4, there were four stimulus conditions: 0 vs. $90^{\circ}$ (vice versa) and 45 vs. $135^{\circ}$ (vice versa). As every block was

\footnotetext{
${ }^{4}$ Our rationale for this change was to improve signal-to-noise ratio and achieve larger ERP responses. In Experiment1 we had considerably smaller evoked potentials, e.g., on Figure 3, at $\mathrm{Oz}$ channel ERPs are around $5.5 \mu \mathrm{V}$ in amplitude, than in Experiment2, where the same ERPs were around $9 \mu \mathrm{V}$ in amplitude (Figure 6).
}

Table 4 | Stimuli in the oddball sequences in Experiment 2.

\begin{tabular}{|c|c|c|c|c|}
\hline \multirow[b]{2}{*}{ Oddball1 } & \multicolumn{2}{|c|}{ Standard } & \multicolumn{2}{|c|}{ Deviant } \\
\hline & $0^{\circ}$ & - & $90^{\circ}$ & I \\
\hline Oddball2 & $90^{\circ}$ & I & $0^{\circ}$ & - \\
\hline Oddball3 & $45^{\circ}$ & 1 & $135^{\circ}$ & 1 \\
\hline Oddball4 & $135^{\circ}$ & 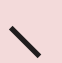 & $45^{\circ}$ & 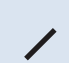 \\
\hline
\end{tabular}

Line segments solely illustrate the orientation of Gábor patches. The standarddeviant pairs highlighted by the same color were used to calculate difference waves.

repeated twice, there were eight blocks presented altogether, and all of them were intended to measure vMMN.

Analysis. For each subject an average of 134.6 epochs $(S D=$ 8.9, range: 99-147) was included in the mean response to deviants, and 249.6 epochs $(S D=16.9$, range: $173-272)$ in the standard response. Analysis was identical with Experiment 1 , with the following exceptions. For every stimuli condition we determined the latency of the vMMN response, based on the grand average difference waveforms. The latency was measured at the channel where difference wave reached its maxima between 100 and $250 \mathrm{~ms}$. Mean amplitudes of the deviant-minusstandard difference wave were measured around this latency in $60 \mathrm{~ms}$ wide windows, in the same time interval for every subjects.

For statistical analyses of vMMN a $2 \times 3$ grid of parietal and occipital channels were used (PO3, POz, PO4; PO7, Oz, PO8). Repeated measures ANOVA was applied on the mean amplitude values of the difference wave including factors cardinality (cardinal: 0 and $90^{\circ}$; oblique: 45 and $135^{\circ}$ ), anteriority (anterior: PO3, $\mathrm{POz}, \mathrm{PO} 4$; posterior: $\mathrm{PO} 7, \mathrm{Oz}, \mathrm{PO} 8$ ) and laterality (left: PO3, PO7; midline: $\mathrm{POz}, \mathrm{Oz}$; right: $\mathrm{PO} 4, \mathrm{PO} 8)$.

Orientation-related amplitude differences were analyzed in two time-intervals, between 100 and $140 \mathrm{~ms}$ for N1a component and between 150 and $190 \mathrm{~ms}$ for N1b component.

\section{RESULTS}

\section{Behavioral results}

Repeated measures ANOVA on tracking efficiency with factor cardinality revealed no significant effects. Tracking efficiency was $78.9 \%(S E=1.56 \%)$ in cardinal blocks and $79.6 \%(S E=1.59 \%)$ in oblique blocks.

\section{ERP results}

As Figure 6A shows, similar waveforms were obtained for standard and deviant stimuli as before. On Oz channel P1-N1a-P2 sequence was elicited, with similar latencies (94, 116, and $240 \mathrm{~ms}$ ) as in the previous experiment. The occipito-temporal N1b component with $180 \mathrm{~ms}$ peak latency was more pronounced in this experiment. 
Visual mismatch negativity. In the four conditions (0, 45, 90, and $135^{\circ}$ ) deviant-minus-standard difference waves were calculated (see Figure 6A). Visual inspection and point-by-point $t$-tests revealed that vMMN responses were present in every condition between 100 and $200 \mathrm{~ms}$, with maxima between 134 to $162 \mathrm{~ms}$ (see Table 5). On anterior channels positive components were present with similar latencies as the posterior vMMNs. Around 270 and $340 \mathrm{~ms}$ the difference waves were positive with a parieto-occipital maximum scalp-distribution.

In a repeated measures ANOVA on mean vMMN amplitudes with factors cardinality, anteriority and laterality a main effect of cardinality $F_{(1,18)}=5.3, p<0.05, \eta^{2}=0.23$ was obtained, revealing more negative amplitudes in response to cardinal stimuli.

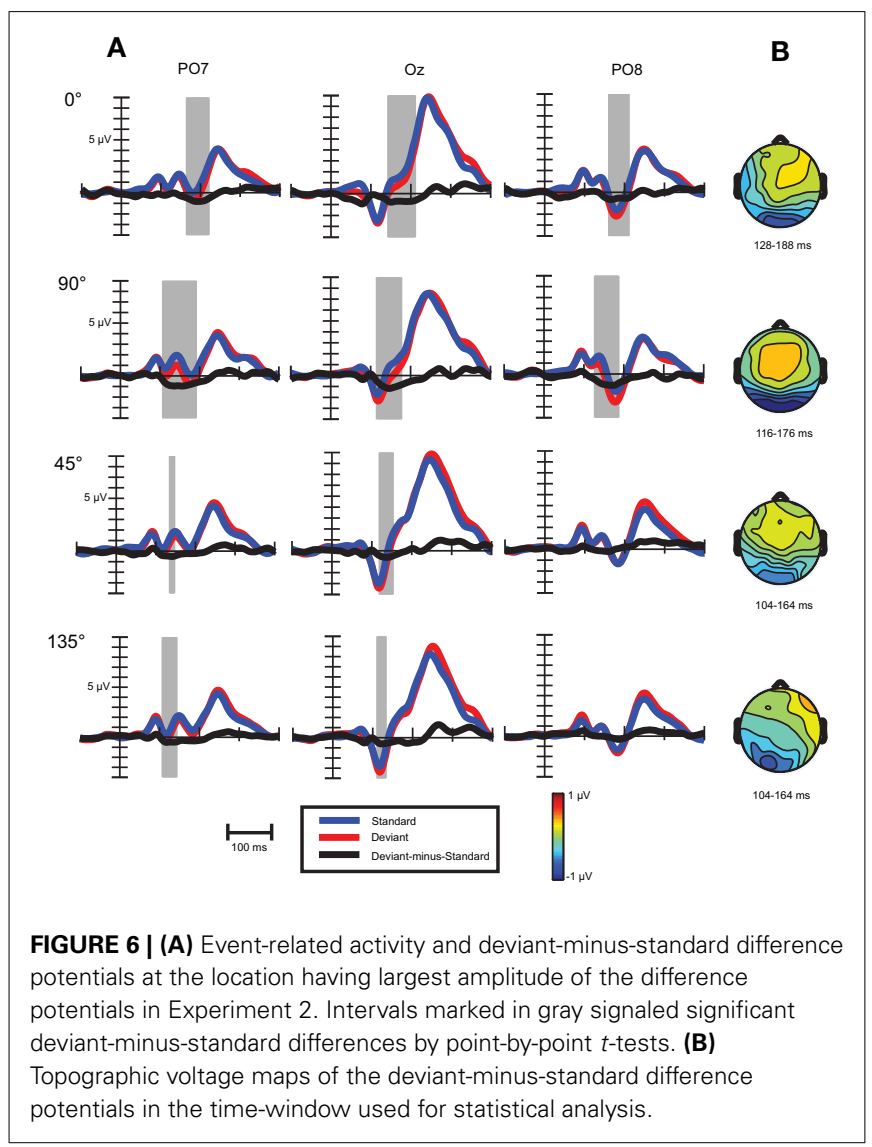

Table 5 | Mean peak amplitudes and mean latencies used for statistical analyses.

\begin{tabular}{llllll}
\hline & $\begin{array}{l}\text { Mean peak } \\
\text { amplitude } \\
(\boldsymbol{\mu} \mathbf{V})\end{array}$ & $\begin{array}{l}\text { Mean } \\
\text { latency } \\
(\mathbf{m s})\end{array}$ & $\begin{array}{l}\text { Mean peak } \\
\text { amplitude } \\
(\boldsymbol{\mu} \mathbf{V})\end{array}$ & $\begin{array}{l}\text { Mean } \\
\text { latency } \\
(\mathbf{m s})\end{array}$ \\
\hline $0^{\circ}$ & Cardinal & -0.67 & 155 & -0.50 & 162 \\
$90^{\circ}$ & & & & -0.84 & 148 \\
$45^{\circ}$ & Oblique & -0.36 & 135 & -0.35 & 134 \\
$135^{\circ}$ & & & & -0.37 & 136
\end{tabular}

For investigating peak latency differences repeated measures ANOVA was performed with the same factors as above. A cardinality main effect emerged, $F_{(1,18)}=55.0, p<0.00001, \eta^{2}=$ 0.75 , which was due to faster latencies in response to oblique angles. We also found an anteriority main effect, $F_{(1,18)}=17.2$, $p<0.001, \eta^{2}=0.49$, reflecting faster latencies at anterior row of channels (142 vs. $148 \mathrm{~ms}$ ).

The question arises whether latency differences reflect earlier timing of vMMN to oblique conditions. Since both waveforms and topographical voltage maps exhibited close concordance in cardinal $\left(0\right.$ and $\left.90^{\circ}\right)$ and oblique $\left(45\right.$ and $\left.135^{\circ}\right)$ stimuli conditions, we collapsed these responses, Figure 7 shows these records.

As a descriptive analysis of onset and offset times Table 6 displays the first time points where point-by-point $t$-tests were significant in the time intervals of cardinal and oblique vMMN responses. Differences between these conditions are notable in offset times only, which suggest that latency differences between oblique and cardinal conditions does not imply earlier timing for oblique vMMNs.

Exogenous differences. Figure 8 depicts visual evoked potentials to four standards $\left(0,45,90\right.$, and $\left.135^{\circ}\right)$. Orientation-related amplitude differences were evident already in the time interval of the Nla component around $120 \mathrm{~ms}$ post-stimulus. Response amplitudes to vertical $\left(90^{\circ}\right)$ and marginally to horizontal $\left(0^{\circ}\right)$ appeared to be less negative than to oblique orientations.

Repeated measures ANOVA conducted with factors stimulus $\left(0,45,90\right.$, and $\left.135^{\circ}\right)$ and channels (PO7, O1, Oz, O2, PO8) revealed that differences are present between orientations. Stimulus main effect was significant, $F_{(3,54)}=11.61, \varepsilon=0.89$, $p<0.0001, \eta^{2}=0.39$. Post-hoc tests inform that it was due to significant differences between amplitudes to $90^{\circ}$ and to every other orientation. In addition, a stimulus $\times$ channel interaction was found, $F_{(12,216)}=2.64, \varepsilon=0.32, p<0.05, \eta^{2}=0.13$. According to post-hoc comparisons, responses to $90^{\circ}$ differed from responses to $0^{\circ}$ at $\mathrm{O} 1$ and $\mathrm{Oz}$, from responses to $45^{\circ}$ at every channel, and from responses to $135^{\circ}$ at $\mathrm{O} 1, \mathrm{Oz}, \mathrm{O} 2, \mathrm{PO} 8$ channels. Responses to horizontal $\left(0^{\circ}\right)$ differed from oblique orientations only at $\mathrm{Oz}\left(0\right.$ vs. $\left.45^{\circ}\right)$ and at PO8 $\left(0\right.$ vs. $\left.135^{\circ}\right)$. So we

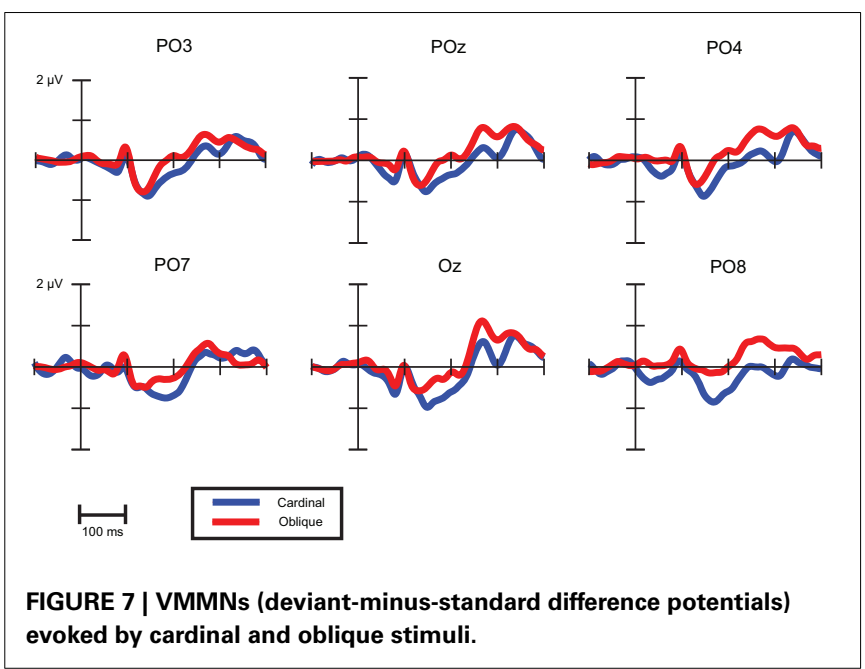


Table 6 | VMMN onset and offset times (in ms) at parieto-occipital channels based on grand-average waveforms.

\begin{tabular}{|c|c|c|c|c|c|c|c|c|c|c|c|c|}
\hline & \multicolumn{2}{|c|}{ PO3 } & \multicolumn{2}{|c|}{$\mathrm{POz}$} & \multicolumn{2}{|c|}{ PO4 } & \multicolumn{2}{|c|}{ PO7 } & \multicolumn{2}{|c|}{$\mathrm{Oz}$} & \multicolumn{2}{|c|}{ P08 } \\
\hline & Onset & Offset & Onset & Offset & Onset & Offset & Onset & Offset & Onset & Offset & Onset & Offset \\
\hline Card. & 112 & 182 & 122 & 168 & 120 & 176 & 106 & 220 & 116 & 196 & 144 & 204 \\
\hline Obl. & 110 & 160 & 116 & 154 & 116 & 150 & 108 & 156 & 112 & 164 & $\mathrm{NaN}$ & $\mathrm{NaN}$ \\
\hline Diff. & 2 & 22 & 6 & 14 & 4 & 26 & -2 & 64 & 4 & 32 & & \\
\hline
\end{tabular}

Last row displays difference between these measures (cardinal minus oblique).

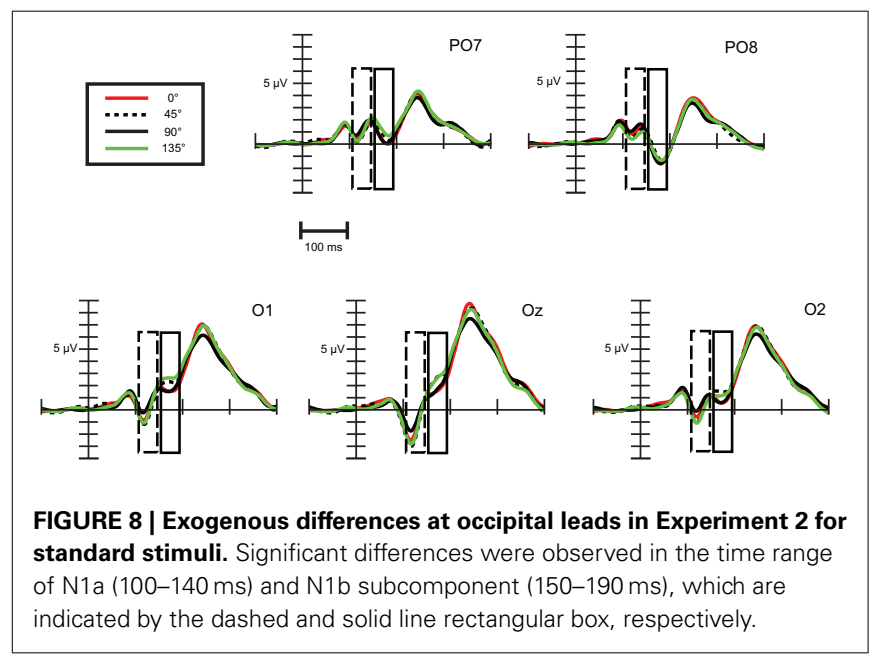

can conclude that around $120 \mathrm{~ms}$ N1a amplitudes to vertical orientation were less negative and horizontal orientation exhibited almost negligible difference.

Differences around $170 \mathrm{~ms}$, in the time-interval of the N1b component were much clearer between orientations. We conducted a repeated measures ANOVA with factors stimulus $(0,45$, 90, and $135^{\circ}$ ) and channels (PO7, O1, Oz, O2, PO8). A stimulus main effect emerged, $F_{(3,54)}=8.96, \varepsilon=0.89, p<0.001$, $\eta^{2}=0.33$, post-hoc tests revealed significant differences between every cardinal-oblique pairs, and no difference between cardinalcardinal and oblique-oblique pairs. We obtained a stimulus $x$ channel interaction, $F_{(12,216)}=4.36, \varepsilon=0.36, p<0.01, \eta^{2}=$ 0.20 . Post-hoc comparisons between cardinal and oblique orientations showed that differences were significant mainly at the three occipital channels $(\mathrm{O} 1, \mathrm{Oz}, \mathrm{O} 2)$, with the exception of 0 vs. $135^{\circ}$ and 90 vs. $135^{\circ}$ contrasts at $\mathrm{O} 2$ channel, which were not significant. At parieto-occipital channels (PO7 and PO8) the differences did not reach significance, with the exception of $0^{\circ}$ vs. $45^{\circ}$ contrast. Summing up, orientation-related differences in Experiment 2 were significant only in the occipital area, but eventually we could replicate the findings of the previous experiment about the orientation-related N1b differences.

\section{DISCUSSION FOR EXPERIMENT 2}

Results in this session reflect that reliable orientation vMMN with Gábor patches could be obtained with the largest possible $\left(90^{\circ}\right)$ orientation change. Oblique effect was found; vMMN to cardinal angles exhibited larger amplitudes and had $20 \mathrm{~ms}$ longer peak latencies. The vMMN to cardinal orientations had similar onset times than oblique vMMN, but its latency was prolonged due to larger amplitude and later offset. Orientation-related amplitude differences were present already around $120 \mathrm{~ms}$, but the oblique effect could be observed only around $170 \mathrm{~ms}$, in the time-interval of N1b component.

\section{GENERAL DISCUSSION}

The main question of our study was whether an important feature of the visual system, the increased sensitivity for cardinal (horizontal and vertical) orientations (so-called oblique effect) influences pre-attentive processing reflected by the vMMN.

In our first experiment $50^{\circ}$ deviancy did not elicit reliable vMMN. Nonetheless the largest possible orientation deviancy, $90^{\circ}$ did elicit vMMN. The deviant-minus-standard difference wave was maximal over occipital areas between 120 and $200 \mathrm{~ms}$, its peak falling between 134 and $162 \mathrm{~ms}$. Stimuli changing from cardinal to cardinal orientations evoked longer and larger responses exhibiting a variant of the oblique effect.

Other studies investigating orientation vMMN obtained reliable vMMN in response to smaller deviances than we did. Czigler and Sulykos (2010) observed vMMN to bar stimuli changing from oblique to oblique orientations using 30 and $60^{\circ}$ deviances. Astikainen et al. (2008) was able to register vMMN to $36^{\circ}$ orientation changes for stimuli changing from oblique to oblique orientations. In the interference condition of the experiment of Sulykos et al. (2013) $30^{\circ}$ deviances evoked vMMN. They were using similar Gábor stimuli as we did, but only in the lower visual field. Kimura et al. $(2009,2010 \mathrm{a})$ presented $36^{\circ}$ deviances and they also obtained vMMN. However, there is one important issue that we should consider. In our experiment every source of external orientation clues was removed. It was achieved by using a circular aperture over the screen, by providing no background light and by presenting stimuli in upper and lower visual field as well. In this way only orientation clues from the vestibular and somatosensory system remained available for the subjects. The studies mentioned above did not control this aspect, so it is possible that e.g., the outline of the computer screen facilitated the evaluation of orientation and the operation of automatic deviance detection.

It is a key question how we could interpret that we obtained increased response to cardinal changes. Although it was not directly assessed in lot of vMMN studies, presumably it is tenable assumption that the stronger the rule, the larger is the response to its violation, simply because change approximates the threshold of the vMMN system in more experimental trials. 
Representation of cardinal stimuli is more potent in the visual system, so their presence and deviations from them are more easily detected. While we were able to register electrophysiological responses reflecting fine differentiation of orientation between 150 and 190 ms over the occipital areas, and we could assume that the brain precisely mapped the orientation of Gábor patches, this occurred later than the vMMN, which appeared around $120 \mathrm{~ms}$ after stimulus onset. Still this argument does not account for why the response was also more sustained, and not just a simple amplitude differences was observed.

The oblique effect found in vMMN might correspond to the magnitude of deviance effect first observed in auditory processing (Näätänen et al., 1982; Sams et al., 1985, but see Horváth et al., 2008). In the case of the auditory MMN, larger deviancy between standard and deviant stimulus results in a MMN response with larger amplitudes and shorter latencies (Kujala et al., 2007). The existence of this phenomenon in visual domain is uncertain. Czigler and Sulykos (2010) obtained similar vMMNs to 30 and $60^{\circ}$ deviancy with stimuli changing from oblique to oblique orientations. Maekawa et al. (2005) used windmill patterns, and according to their results, vMMN (or as they label it, "deviantrelated negativity," DRN) did not show increase of amplitude with increasing magnitude of deviance, only the latency decreased of the second negativity between 200 and 300 ms with maxima over temporal areas.

In our study, stimuli changing from cardinal to cardinal could be regarded as a stronger stimulus, and the perceived difference between them larger than the difference between oblique orientations, even though differences were the exact same in degrees. We interpret the sustained response to the more salient cardinal changes, as an indication of the visual system submitting more computational resources to changes that could be of larger importance.

Recently Cléry et al. (2013) found another version of magnitude of deviance effect using fMRI and a passive oddball paradigm. In their experiment the shape of the circular stimuli changed dynamically, for standard stimuli it stretched out horizontally into an ellipse, for deviant stimuli it stretched out vertically. The novel stimuli changed gradually to an irregular shape. The differences between responses elicited by deviant and novel stimuli were apparent in the visual cortex (BA 18 and 19) and in the medial frontal cortex (BA 8). In the anterior cingular cortex only novel stimuli evoked significant activity compared to baseline. Despite the fact that fMRI and ERP results are sometimes difficult to compare due to their widely different spatial and temporal resolution, in this case some parallels could be drawn. According to the authors extrastriatal differences might signal the activation of the visual areas that are responsible for the vMMN generation (or for other higher sensory processes), while differential fMRI response in the anterior cingular cortex might show the contribution of the areas responsible for the generation of the P3a component that is usually elicited by novel, non-target stimuli (Courchesne et al., 1975). However, because in this experiment the type of deviancy between the standard and deviant stimuli (vertical or horizontal stretching) was not the same as the deviancy between the deviant and novel stimuli (vertical stretching or changing to an irregular shape), it is difficult to compare their results with ours. Still, it seems that generators of the posterior part of vMMN are able to give not only all-or-nothing responses to visual deviancies.

We also found exogenous, orientation-related differences around $150-190 \mathrm{~ms}$ in the amplitude of the ERPs evoked by the standard stimuli. It is an important question why we observed these differences in a latency range which is quite late in time for visual orientation processing. The area V1 contains cells selective for orientation, and Gábor patches stimulate these as well. Visual processing in the striatal area (V1) is signaled by the $\mathrm{C} 1$ visual evoked potential, 50-90 ms after stimulus onset (Clark et al., 1995). Surprisingly, not too many studies reported (e.g., Song et al., 2010) orientation-related differences in this component. Unfortunately we were not able to examine this component due to simultaneous stimulation of upper and lower visual fields.

The first signs of orientation-related processing emerged between 100 and $140 \mathrm{~ms}$ in Experiment 2, where vertical $\left(90^{\circ}\right)$ stimuli elicited less negative N1a component than the other stimuli. Horizontal orientations evoked slightly different response than oblique stimuli. Arakawa et al. (2000) found oblique effect in the P100 component; at low spatial frequencies ERPs to cardinal orientations exhibited longer latencies than those to oblique stimuli, while at high spatial frequencies the relationship was reversed. Proverbio et al. (2002) reported orientation-related differences in P1 and P3 components, vertical elicited larger amplitudes than oblique stimuli (they did not look at horizontal stimuli). A study conducted by Yoshida et al. (1975) found differences in N1-P2 peak-to-peak amplitude, cardinal stimuli evoked larger responses than oblique stimuli. They obtained waveforms similar to ours using circular black and white gratings as stimuli, a P1-N1-P2 sequence was elicited with peak latencies of 110-120, 180-190, and 270-280 ms, respectively. Since they used only one active electrode $(\mathrm{Oz})$, it is unclear whether $\mathrm{N} 1$ in their study had similar scalp topography as ours.

Our knowledge about the N1b wave is rather limited. This occipito-temporal component usually peaks approximately around 170-180 ms. In the experiment of Clark and Hillyard (1996) it was maximal at $180 \mathrm{~ms}$, it was elicited by nontarget circular black and white checkerboards on contralateral sides. In our experiment this wave displayed bilateral distribution due to bilateral stimulus presentation. In the Clark and Hillyard (1996) study target stimuli evoked larger N1b responses, but the latency and scalp topography remained unaffected. The authors localized this component to the ventral-lateral visual cortex. This extrastriatal area is engaged in object identification and belongs to ventral visual pathway (Ungerleider and Haxby, 1994). This raises the possibility that in our experiments the visual system treated Gábor patches as objects and reprocessed the orientation of these objects during N1b. Others using everyday objects pointed out that processing of the orientation of objects could be tied to the dorsal occipito-parietal system (Valyear et al., 2006), so it is unclear what are the brain sources of the N1b component that we obtained in the present experiment. Examining the role of attention, Hopf et al. (2002) showed that a negativity with $165 \mathrm{~ms}$ peak amplitude is increased if subjects perform a discrimination task compared to simple detection. In our study Gábor patches were unattended, so presumably only detection took place, and the 
N1b modulation was clearly a result of difference in the physical characteristics of the stimuli.

To sum up the visual evoked potentials to standard stimuli provided evidence that orientation-related processing could be tracked until $190 \mathrm{~ms}$ after stimulus onset. Although vertical stimuli elicited different N1a in an earlier time interval (around $120 \mathrm{~ms}$ ), N1b was the one that precisely mapped the orientation of stimuli. While theoretical assumptions suggest that Gábor patches are primarily processed in V1, it is possible that extrastriatal areas play a role in it as well-our findings corroborate this notion. The vMMN emerged earlier (onset time $\sim 120 \mathrm{~ms}$ ) than N1b (around $170 \mathrm{~ms}$ ) in both cardinal and oblique stimuli conditions. It is possible that the precise orientation of the stimuli was achieved only after the process marked by N1b, and the visual deviance detection was not able to utilize this input. This could account for the widely different thresholds of visual deviance detection in the passive $\left(90^{\circ}\right)$ and active paradigm $\left(10-17^{\circ}\right)$.

The other feasible explanation is that the orientation of stimuli is determined in earlier levels of visual processing, possibly in $\mathrm{V} 1$, and the N1b component only signals the reprocessing of the stimulus as an object. In this case we can conclude that vMMN did not emerge to some of the differences that the visual system can detect, but only for considerably larger differences that exceed its own threshold.

Other studies provided further evidence that the sensitivity of active visual deviance detection is independent of the vMMN. In the experiment of Czigler et al. (2007) vMMN could be registered if the SOA between the stimulus and the backward mask was at least $40 \mathrm{~ms}$. However if the stimulus_-mask SOA was increased up to $174 \mathrm{~ms}$, the magnitude of the vMMN remained the same. In attended conditions participants responded to deviants with a Go-NoGo response. In this case performance increased monotonically up to the longest stimulus-mask SOA (174 ms). Lyyra et al. (2012) combined change blindness paradigm and vMMN. Change blindness labels the phenomenon that human subjects are usually slow or unable to detect sudden, but minor changes in successive pictures of complex, natural scenes. The authors presented such pictures in oddball sequences while subjects tried to detect the change. They looked into the ERPs until the point when

\section{REFERENCES}

Alho, K., Woods, D. L., Algazi, A., and Näätänen, R. (1992). Intermodal selective attention. II. Effects of attentional load on processing of auditory and visual stimuli in central space. Electroencephalogr. Clin. Neurophysiol. 82, 356-368. doi: 10.1016/0013-4694(92)90005-3

Andrews, D. P. (1967). Perception of contour orientation in the central fovea. I. Short lines. Vision Res. 7, 975-997. doi: 10.1016/00426989(67)90014-4

Arakawa, K., Tobimatsu, S., KuritaTashima, S., Nakayama, M., Kira, J. I., and Kato, M. (2000). Effects

the detection of change happened. The authors hypothesized that vMMN will emerge even before the behavioral detection. Successful behavioral change detection occurred in the absence of vMMN using $500 \mathrm{~ms}$ inter-stimulus interval (ISI), probably because during this interval sensory memory crucial for vMMN elicitation decayed. With a shorter, $100 \mathrm{~ms}$ ISI, behavioral change detection was unchanged, but this time vMMN also emerged in posterior areas. What pertains to our question is that vMMN was not a necessary prerequisite of explicit change detection in their study. Our results also suggest similar dissociations; the processes responsible for the discrimination performance in the active paradigm are not the same as those generating vMMN.

While in the auditory modality, the threshold for MMN more or less corresponds to the behavioral threshold in an active, attended paradigm; in the visual domain it seems not to be the case. Alho et al. (1992) presented rectangular black and white gratings in their experiment, the deviant stimuli differed from standard in height. Only the larger of the two deviances elicited posterior negativity. In the study of Czigler et al. (2002) coloredblack gratings were presented, and the results were similar: only larger deviancy evoked vMMN. In summary, this phenomenon was demonstrated with three different types of visual deviancyshape, color, and orientation.

It is of particular interest what the functional significance of this dissimilar sensitivity is. The auditory MMN could serve as a basis of subsequent orienting response, and vMMN might have a similar role (see Czigler et al., 2006). It would not be functional if every discriminable change in a sequence elicited an orienting reaction, because it would lead to unnecessary distraction from the primary task. In addition, since humans gather information mainly from vision, the processing of stimuli in the focus of attention is substantial, and stimulation in the background is secondary. Auditory perception operates often outside the focus of attention, so automatic, unconscious perceptual processes might have a more central role than in vision.

\section{ACKNOWLEDGMENTS}

We thank Zsuzsanna D'Albini for data collection. This study was supported by the National Research Fund of Hungary (OTKA 104462).

Neurosci. Lett. 368, 231-234. doi: 10.1016/j.neulet.2004.07.025

Berkley, M. A., Kitterle, F., and Watkins, D. W. (1975). Grating visibility as a function of orientation and retinal eccentricity. Vision Res. 15, 239-244. doi: 10.1016/0042-6989(75)90213-8

Caelli, T., Brettel, H., Rentschler, I., and Hilz, R. (1983). Discrimination thresholds in the two-dimensional spatial frequency domain. Vision Res. 23, 129-133. doi: 10.1016/00426989(83)90135-9

Campbell, F. W., Kulikowski, J. J., and Levinson, J. (1966). Effect of orientation on visual resolution of gratings. J. Physiol. 187, 427-436.
Cavanagh, P., Arguin, M., and Treisman, A. (1990). Effect of surface medium on visual search for orientation and size features. J. Exp. Psychol. Hum. Percept. Perform. 16, 479-491. doi: 10.1037/0096-1523.16.3.479

Clark, V. P., and Hillyard, S. A. (1996). Spatial selective attention affects early extrastriate but not striate components of the visual evoked potential. J. Cogn. Neurosci. 8, 387-402. doi: 10.1162/jocn.1996.8.5.387

Clark, V. P., Fan, S., and Hillyard, S. A. (1995). Identification of early visual evoked potential generators by 
retinotopic and topographic analyses. Hum. Brain Mapp. 2, 170-187. doi: $10.1002 / \mathrm{hbm} .460020306$

Clery, H., Andersson, F., BonnetBrilhault, F., Philippe, A., Wicker, B., and Gomot, M. (2013). fMRI investigation of visual change detection in adults with autism. Neuroimage Clin. 2, 303-312. doi: 10.1016/j.nicl.2013.01.010

Cléry, H., Andersson, F., Fonlupt, P., and Gomot, M. (2013). Brain correlates of automatic visual change detection. Neuroimage 75, 117-122. doi: 10.1016/j.neuroimage.2013. 02.050

Clery, H., Roux, S., Besle, J., Giard, M. H., Bruneau, N., and Gomot, M. (2012). Electrophysiological correlates of automatic visual change detection in school-age children. Neuropsychologia 50, 979-987. doi: 10.1016/j.neuropsychologia.2012. 01.035

Coppola, D. M., White, L. E., Fitzpatrick, D., and Purves, D. (1998). Unequal representation of cardinal and oblique contours in ferret visual cortex. Proc. Natl. Acad. Sci. U.S.A. 95, 2621-2623. doi: 10.1073/pnas.95.5.2621

Corwin, T. R., Moskowitz-Cook, A., and Green, M. A. (1977). The oblique effect in a vernier acuity situation. Percept. Psychophys. 21, 445-449. doi: 10.3758/BF03199500

Courchesne, E., Hillyard, S. A., and Galambos, R. (1975). Stimulus novelty, task relevance and the visual evoked potential in man. Electroencephalogr. Clin. Neurophysiol. 39, 131-143. doi: 10.1016/0013-4694(75)90003-6

Czigler, I. (2007). Visual mismatch negativity. J. Psychophysiol. 21, 224-230. doi: 10.1027/0269-8803.21.34.224

Czigler, I., Balázs, L., and Pató, L. G. (2004). Visual change detection: event-related potentials are dependent on stimulus location in humans. Neurosci. Lett. $\quad 364, \quad 149-153 . \quad$ doi: 10.1016/j.neulet.2004.04.048

Czigler, I., Balázs, L., and Winkler, I. (2002). Memory-based detection of task-irrelevant visual change. Psychophysiology 39, 869-873. doi: 10.1111/1469-8986.3960869

Czigler, I., and Pató, L. (2009). Unnoticed regularity violation elicits change-related brain activity. Biol. Psychol. 80, 339-347. doi: 10.1016/j.biopsycho.2008.12.001

Czigler, I., and Sulykos, I. (2010). Visual mismatch negativity to irrelevant changes is sensitive to taskrelevant changes. Neuropsychologia 48, 1277-1282. doi: 10.1016/ j.neuropsychologia.2009.12.029
Czigler, I., Weisz, J., and Winkler, I. (2007). Backward masking and visual mismatch negativity: Electrophysiological evidence for memory-based detection of deviant stimuli. Psychophysiology 44, 610-619. doi: 10.1111/j.14698986.2007.00530.x

Czigler, I., Winkler, I., Pató, L., Várnagy, A., Weisz, J., and Balázs, L. (2006). Visual temporal window of integration as revealed by the visual mismatch negativity event-related potential to stimulus omissions. Brain Res. 1104, 129-140. doi: 10.1016/j.brainres.2006.05.034

Flynn, M., Liasis, A., Gardner, M., Boyd, S., and Towell, T. (2009). Can illusory deviant stimuli be used as attentional distractors to record vMMN in a passive three stimulus oddball paradigm. Exp. Brain Res. 197, 153-161. doi: 10.1007/s00221009-1901-7

Furmanski, C. S., and Engel, S. A. (2000). An oblique effect in human primary visual cortex. Nat. Neurosci. 3, 535-536. doi: 10.1038/75702

Gentaz, E., Luyat, M., Cian, C., Hatwell, Y., Barraud, P. A., and Raphel, C. (2001). The reproduction of vertical and oblique orientations in the visual, haptic, and somato-vestibular systems. $Q$. J. Exp. Psychol. A 54, 513-526. doi: 10.1080/713755970

Guthrie, D., and Buchwald, J. S. (1991). Significance testing of difference potentials. Psychophysiology 28, 240-244. doi: 10.1111/j.14698986.1991.tb00417.x

Heslenfeld, D. J. (2003). "Visual mismatch negativity," in Detection of Change: Event-Related Potential and fMRI Findings, ed J. Polich (Boston, MA: Kluver Academic Press), 41-59.

Hopf, J. M., Vogel, E., Woodman, G., Heinze, H. J., and Luck, S. J. (2002). Localizing visual discrimination processes in time and space. J. Neurophysiol. 88, 2088-2095.

Horváth, J., Czigler, I., Jacobsen, T., Maess, B., Schröger, E., and Winkler, I. (2008). MMN or no MMN: no magnitude of deviance effect on the MMN amplitude. Psychophysiology 45, 60-69. doi: 10.1111/j.1469-8986. 2007.00599.x

Kimura, M., Katayama, J., Ohira, H., and Schröger, E. (2009). Visual mismatch negativity: new evidence from the equiprobable paradigm. Psychophysiology 46, 402-409. doi: 10.1111/j.1469-8986.2008.00767.x

Kimura, M., Schröger, E., and Czigler, I. (2011). Visual mismatch negativity and its importance in visual cognitive sciences.
Neuroreport 22, 669-673. doi: 10.1097/WNR.0b013e32834973ba

Kimura, M., Schröger, E., Czigler, I., and Ohira, H. (2010a). Human visual system automatically encodes sequential regularities of discrete events. J. Cogn. Neurosci. 22, 1124-1139. doi: $10.1162 /$ jocn.2009. 21299

Kimura, M., Ohira, H., and Schröger, E. (2010b). Localizing sensory and cognitive systems for preattentive visual deviance detection: an SLORETA analysis of the data of Kimura, et al. (2009). Neurosci. Lett. 485, 198-203. doi 10.1016/j.neulet.2010.09.011

Koelewijn, L., Dumont, J. R., Muthukumaraswamy, S. D., Rich, A. N., and Singh, K. D. (2011). Induced and evoked neural correlates of orientation selectivity in human visual cortex. Neuroimage 54, 2983-2993. doi: 10.1016/j.neuroimage.2010.11.045

Kujala, T., Tervaniemi, M., and Schröger, E. (2007). The mismatch negativity and clinical neuroscience: theoretical and methodological considerations. Biol. Psychol. 74, 1-19. doi: 10.1016/j.biopsycho. 2006.06.001

Levitt, J. B., Kiper, D. C., and Movshon, J. A. (1994). Receptive fields and functional architecture of macaque V2. J. Neurophysiol. 71, 2517-2542.

Li, B., Peterson, M. R., and Freeman, R. D. (2003). Oblique effect: a neural basis in the visual cortex. J. Neurophysiol. 90, 204-217. doi: 10.1152/jn.00954.2002

Lipshits, M., and McIntyre, J. (1999). Gravity affects the preferred vertical and horizontal in visual perception of orientation. Neuroreport 10 1085-1089. doi: 10.1097/00001756199904060-00033

Lyyra, P., Wikgren, J., Ruusuvirta, T., and Astikainen, P. (2012). Explicit behavioral detection of visual changes develops without their implicit neurophysiological detectability. Front. Hum. Neurosci. 6:48. doi: 10.3389/fnhum.2012 00048

Maekawa, T., Goto, Y., Kinukawa, N., Taniwaki, T., Kanba, S., and Tobimatsu, S. (2005). Functional characterization of mismatch negativity to visual stimulus. Clin. Neurophysiol. 116 2392-2402. doi: 10.1016/j.clinph. 2005.07.006

Maffei, L., and Campbell, F. W. (1970). Neurophysiological localization of the vertical and horizontal visual coordinates in man. Science 167, 386-387. doi: 10.1126/science.167. 3917.386
Mansfield, R. J. W. (1974). Neural basis of the orientation preference in primates. Science 186, 1133-1135. doi: 10.1126/science.186.4169.1133

Marendaz, C. (1998). Nature and dynamics of reference frames in visual search for orientation: Implications for early visual processing. Psychol. Sci. 9, 27-32. doi: 10.1111/1467-9280.00005

May, J. G., Cullen, J. K. Jr., MoskowitzCook, A., and Siegfried, J. B. (1979). Effects of meridional variation on steady-state visual evoked potentials. Vision Res. 19, 1395-1401. doi: 10.1016/0042-6989(79)90213-X

Mitchell, D. E., Freeman, R. D., and Westheimer, G. (1967). Effect of orientation on the modulation sensitivity for interference fringes on the retina. J. Opt. Soc. Am. A. 57, 246-249. doi: 10.1364/JOSA.57.000246

Moskowitz, A., and Sokol, S. (1985). Effect of stimulus orientation on the latency and amplitude of the VEP. Invest. Ophthalmol. Vis. Sci. 26, 246-248.

Müller, D., Roeber, U., Winkler, I., Trujillo-Barreto, N., Czigler, I., and Schröger, E. (2012). Impact of lower- vs. upper-hemifield presentation on automatic colour-deviance detection: a visual mismatch negativity study. Brain Res. 1472, 89-98. doi: 10.1016/j.brainres.2012.07.016

Näätänen, R., Paavilainen, P., Rinne, T., and Alho, K. (2007). The mismatch negativity (MMN) in basic research of central auditory processing: a review. Clin. Neurophysiol. 118, 2544-2590. doi: 10.1016/j.clinph.2007.04.026

Näätänen, R., Simpson, M., and Loveless, N. E. (1982). Stimulus deviance and evoked potentials. Biol. Psychol. 14, 53-98. doi: 10.1016/0301-0511(82)90017-5

Näätänen, R., and Winkler, I. (1999). The concept of auditory stimulus representation in cognitive neuroscience. Psychol. Bull. 125, 826-859. doi: 10.1037/0033-2909.125.6.826

Pazo-Alvarez, P., Amenedo, E., and Cadaveira, F. (2004). Automatic detection of motion direction change in the human brain. Eur. J. Neurosci. 19, 1978-1986. doi: 10.1111/j.1460-9568.2004.03273.x

Pazo-Alvarez, P., Cadaveira, F., and Amenedo, E. (2003). MMN in the visual modality: a review. Biol. Psychol. 63, 199-236. doi: 10.1016/S0301-0511(03)00049-8

Proverbio, A. M., Esposito, P., and Zani, A. (2002). Early involvement of the temporal area in attentional selection of grating orientation: An ERP 
study. Brain Res. Cogn. Brain Res. 13, 139-151. doi: 10.1016/S09266410(01)00103-3

Sams, M., Paavilainen, P., Alho, K., and Näätänen, R. (1985). Auditory frequency discrimination and event-related potentials. Electroencephalogr. Clin. Neurophysiol. 62, 437-448. doi: 10.1016/0168-5597(85)90054-1

Skrandies, W. (1984). Scalp potential fields evoked by grating stimuli: effects of spatial frequency and orientation. Electroencephalogr. Clin. Neurophysiol. 58, 325-332. doi: 10.1016/0013-4694(84)90058-0

Song, Y., Sun, L., Wang, Y., Zhang, X., Kang, J., Ma, X., et al. (2010). The effect of short-term training on cardinal and oblique orientation discrimination: an ERP study. Int. J. Psychophysiol. 75, 241-248. doi: 10.1016/j.ijpsycho. 2009.11.007

Sulykos, I., and Czigler, I. (2011). One plus one is less than two: visual features elicit non-additive mismatch-related brain activity. Brain Res. 1398, 64-71. doi: 10.1016/j.brainres.2011.05.009

Sulykos, I., Kecskés-Kovács, K., and Czigler, I. (2013). Mismatch negativity does not show evidence of memory reactivation in the visual modality. J. Psychophysiol. 27, 1-6. doi: 10.1027/0269-8803/a000085

Tales, A., Newton, P., Troscianko, T., and Butler, S. (1999). Mismatch negativity in the visual modality. Neuroreport 10, 3363-3367. doi: 10.1097/00001756-199911080 $-00020$

Treisman, A., and Gormican, S. (1988). Feature analysis in early vision: evidence from search asymmetries. Psychol. Rev. 95, 15-48. doi: 10.1037/0033-295X.95.1.15

Ungerleider, L. G., and Haxby, J. V. (1994). 'What' and 'where' in the human brain. Curr. Opin. Neurobiol. 4, 157-165. doi: 10.1016/0959-4388(94)90066-3

Urakawa, T., Inui, K., Yamashiro, K., Tanaka, E., and Kakigi, R. (2010). Cortical dynamics of visual change detection based on sensory memory. Neuroimage 52, 302-308. doi: 10.1016/j.neuroimage.2010.03.071

Valyear, K. F., Culham, J. C., Sharif, N., Westwood, D., and Goodale, M. A. (2006). A double dissociation between sensitivity to changes in object identity and object orientation in the ventral and dorsal visual streams: a human fMRI study. Neuropsychologia 44, 218-228. doi: 10.1016/ j.neuropsychologia.2005.05.004
Vidyasagar, T. R., and Urbas, J. V. (1982). Orientation sensitivity of cat LGN neurons with and without inputs from visual cortical areas 17 and 18. Exp. Brain Res. 46, 157-169. doi: 10.1007/BF00237172

Winkler, I., and Czigler, I. (2012). Evidence from auditory and visual event related potential (ERP) studies of deviance detection (MMN and vMMN) linking predictive coding theories to perceptual object representations. Int. J. Psychophysiol. 83, 132-143. doi: 10.1016/j.ijpsycho. 2011.10.001

Xu, X., Collins, C. E., Khaytin, I., Kaas, J. H., and Casagrande, V. A. (2006). Unequal representation of cardinal vs. oblique orientations in the middle temporal visual area. Proc. Natl. Acad. Sci. U.S.A. 103, 17490-17495. doi: 10.1073/pnas.0608502103

Yoshida, S., Iwahara, S., and Nagamura, N. (1975). The effect of stimulus orientation on the visual evoked potential in human subjects. Electroencephalogr. Clin. Neurophysiol. 39, 53-57. doi: 10.1016/0013-4694(75)90126-1

Yucel, G., McCarthy, G., and Belger, A. (2007). fMRI reveals that involuntary visual deviance processing is resource limited.
Neuroimage 34, 1245-1252. doi: 10.1016/j.neuroimage.2006.08.050

Conflict of Interest Statement: The authors declare that the research was conducted in the absence of any commercial or financial relationships that could be construed as a potential conflict of interest.

Received: 30 April 2013; accepted: 02 September 2013; published online: 23 September 2013.

Citation: Takács E, Sulykos I, Czigler I, Barkaszi I and Balázs L (2013) Oblique effect in visual mismatch negativity. Front. Hum. Neurosci. 7:591. doi: 10.3389/fnhum.2013.00591

This article was submitted to the journal Frontiers in Human Neuroscience.

Copyright (ㄷ) 2013 Takács, Sulykos, Czigler, Barkaszi and Balázs. This is an open-access article distributed under the terms of the Creative Commons Attribution License (CC BY). The use, distribution or reproduction in other forums is permitted, provided the original author(s) or licensor are credited and that the original publication in this journal is cited, in accordance with accepted academic practice. No use, distribution or reproduction is permitted which does not comply with these terms. 